\title{
ASSOCIATION BETWEEN PROTEINURIA AND ACTIVE HELICOBACTER PYLORI INFECTION IN NON-DIABETIC PATIENTS
}

\author{
Mohamed Nagah Balat ${ }^{1}$, Mohamed Ali Fahmy Zanaty ${ }^{1}$, Neveen George EL-Antouny ${ }^{1}$, Haythem \\ Kamal Ahmed ${ }^{2}$. \\ ${ }^{1}$ Internal Medicine Department, Zagazig University, Egypt \\ ${ }^{2}$ Clinical Pathology Department, Zagazig University, Egypt.
}

Received: 4 October 2018

Accepted: 26 December 2018

Corresponding author

Mohamed Nagah Balat

moh.nagah@zu.edu.eg.

\section{ABSTRACT}

Background: The incidence Helicobacter pylori infection and its possible relationship to different diseases are a focus of attention nowadays. Therefore, the aim of this study was to examine the association between proteinuria and active Helicobacter pylori infection in middle age nondiabetic patients.

Material and Methods: A Case-control study was conducted on118 subjects and included 59 patients who suffered from $\mathrm{H}$. pylori infection from October 2017 to April 2018. 59 patients were negative H. pylori infection included and served as a control group. Demographic and clinical data were collected.

Results: The infected H. Pylori group showed a significant higher ACR compared to the control group. In addition, infected H. Pylori group showed a significant lower hemoglobin and albumin compared to the control group.

Conclusion: Patients having H. Pylori infection show a significant elevation in the urinary albumin/creatinine ratio and a significant anemia suggesting a role of $\mathrm{H}$. Pylori infection in the pathogenesis of proteinuria and anemia.

Keywords: Helicobacter pylori, Proteinuria.

\section{INTRODUCTION}

$\mathrm{H}$ . Pylori bacteria is the main pathogenic organism that settles on the gastric mucosa of more than half the human population around the world, with more prominence in the developing countries. ${ }^{[1]} \mathrm{H}$. Pylori had been found to be the main factor in acute and chronic gastritis, peptic ulcer diseases, and in most cases gastric malignancy. Beside to some extra gastro-intestinal diseases. Such as cardiac, pulmonary and hematological diseases. ${ }^{[2][3][4]}$

Helicobacter pylori had been considered to be one of the commonest bacterial infections in human being and its contribution to different diseases still at the core of attention. ${ }^{[5]}$

H. Pylori exclusively colonizes over the epithelium of the stomach, which suggests that it has a precise identification to gastric epithelial cell. H. Pylori produces adhesins in order to adhere to the epithelial cells, by which it binds to carbohydrates and lipids in the membrane of the epithelial cells. ${ }^{[8]}$
Helicobacter pylori colonies over the gastric mucosa can be a trigger for an immune response through bacterial or host dependent cytotoxic agents. ${ }^{[6]}$

By this way, a local inflammatory response can be triggered, although the inflammatory process is limited to the gastric mucosa, this inflammation may have a role in some extragastric disorders. ${ }^{[7]} \mathrm{H}$. Pylori elaborates numerous enzymes that can lead to cellular damage either by direct or indirect pathways. Such as Urease, phospholipase and Catalase enzymes. ${ }^{[9]}$

H. Pylori is not an invasive bacterium, but it fires up severe and powerful immunological and inflammatory reactions in the form of adaptive and innate host immunologic reactions which are vital in the H. Pylori pathogenicity and related disease. Many inflammatory mediators were thought to be involved in the pathogenic way of extra digestive disorders caused by Helicobacter pylori infection which include; leukotriene C4, interleukin-1 (IL-1), 
interferon- (IFN)- $\gamma$ ), interleukin-6(IL-6), platelet-activating factor and tumor necrosis factor alpha- (TNF- $\alpha)$. ${ }^{[10]}$

Proteinuria is a well-known indicator for renal disorders. The relationship between nephrotic range proteinuria (nephrotic syndrome) and hypoalbuminemia, edema, hyperlipidemia, susceptibility to infection, and hypercoagulability state also had been approved. For the last two decades, evidences had been accumulated and showed the presence of a direct inverse influence caused by proteinuria and renal diseases that provoke the progress from chronic kidney disease into endstage renal disease. ${ }^{[11]}$

H. Pylori infection was hypothesized to motivate a strong inflammatory and immunological response. In addition, there were evidences that the inflammatory mediators and cytokines are produced at excessive amounts in this infection. In addition, the crossreaction between the released factors and host immune system can cause gastric and the extradigestive manifestations. In addition, some evidences referred to cytokines as being involved in the increased passage of plasma protein through the glomeruli. [12]

Therefore, the aim of this study is to determine the association between proteinuria and active Helicobacter pylori.

\section{MATERIALS AND METHODS}

This is a Case-control study that included 118 participating subjects from whom 59 patients were infected by H. pylori and 59 patients were negative for $\mathrm{H}$. pylori. All of them were suffering from chronic and recurrent dyspeptic complains. All patients were selected from patients attending the Internal Medicine outpatient clinic of Zagazig University Hospitals in the period between October 2017 and April 2018.

After excluded patients with history of upper GIT bleeding or surgery, Diabetics, with evidence of any hepatic, renal, cardiac or respiratory diseases, pregnancy females. Malignancies, recent history of eradication therapy of Helicobacter pylori infection and PPI intake with two weeks before the study.
Patients were subjected to thorough history taking regarding age, sex, body mass index, arterial blood pressure. Full clinical examination was done.

Routine laboratory investigation were performed according to clinical pathology department of Zagazig university hospitals protocols and included $\mathrm{CBC}$, kidney function tests, liver function tests, complete urine analysis and micro albuminuria, fasting blood glucose, HA1c, total cholesterol and Albumin to creatinine ratio (ACR). Stool samples were taken and examined for the presence of H.Pylori antigen.

Our study groups defined as:

- Group (1): included 59 non-infected H. pylori non-diabetic of both gander who served as a control group.

- Group (2): included 59 infected H. pylori nondiabetic patients of both gander who served as a case group.

\section{Ethical}

Written Informed consent was taken from the patient to participate in the study. Approval for performing the study was obtained from internal medicine Department, Zagazig University Hospitals after taking Institutional Review Board (IRB) approval

\section{Statistical analysis}

All data were collected, tabulated and statistically analyzed using SPSS 24.0 for windows (SPSS Inc., Chicago, IL, USA). Quantitative data were expressed as mean \pm SD (Standard deviation) for parametric and median and range for non-parametric data. Independent $\mathrm{T}$ test and Mann Whitney test were used to calculate difference between quantitative variables in two groups for parametric and nonparametric variables respectively. Pearson's and Spearman's correlation coefficient were used for correlating normal and non-parametric variables. All statistical comparisons were two tailed with significance Level of P-value $\leq 0.05$ indicates significant, $\mathrm{p}<0.001$ indicates highly significant difference while, $\mathrm{P}>0.05$ indicates Non-significant difference. 


\section{RESULTS}

The demographic and clinical features of the patients are described (Table 1).

This table shows a highly significant difference between the two groups as regard albumin/creatinine ratio, serum albumin and hemoglobin.

Table 1 Patients' characteristics between the groups.

\begin{tabular}{|c|c|c|c|}
\hline & Control Group (N=59) & Case Group (N=59) & $\mathrm{P}$ \\
\hline $\begin{array}{l}\text { Age (years) } \\
\text { Mean } \pm \text { SD }\end{array}$ & $31.09 \pm 9.03$ & $32.1 \pm 9.31$ & .772 \\
\hline Female $\mathrm{n}(\%)$ & $27(45.8 \%)$ & $25(42.4 \%)$ & .611 \\
\hline $\begin{array}{c}\text { BMI }\left(\mathrm{kg} / \mathrm{m}^{2}\right) \\
\text { Mean } \pm \text { SD }\end{array}$ & $22.27 \pm 2.61$ & $23.03 \pm 2.42$ & .427 \\
\hline $\begin{array}{c}\text { Systolic blood pressure } \\
\text { Mean } \pm \text { SD }\end{array}$ & $114.09 \pm 7.01$ & $116.75 \pm 10.79$ & .495 \\
\hline $\begin{array}{c}\text { Diastolic blood pressure } \\
\text { Mean } \pm \text { SD }\end{array}$ & $71.36 \pm 8.39$ & $71.5 \pm 10.89$ & .983 \\
\hline $\begin{array}{c}\text { Hemoglobin }(\mathrm{g} / \mathrm{dL}) \\
\text { Mean } \pm \text { SD }\end{array}$ & $12.78 \pm 0.75$ & $10.51 \pm 0.62$ & $<0.001$ \\
\hline $\begin{array}{c}\text { TLC }\left(10^{3} / \mu \mathrm{L}\right) \\
\text { Mean } \pm \mathrm{SD}\end{array}$ & $5.18 \pm 1.14$ & $5.98 \pm 1.09$ & .066 \\
\hline $\begin{array}{c}\text { Platelets }\left(10^{3} / \mu \mathrm{L}\right) \\
\text { Mean } \pm \mathrm{SD}\end{array}$ & $367.27 \pm 62.62$ & $355 \pm 69.39$ & .630 \\
\hline $\begin{array}{c}\text { Creatinine }(\mathrm{mg} / \mathrm{dL}) \\
\text { Mean } \pm \mathrm{SD}\end{array}$ & $0.75 \pm 0.082$ & $0.75 \pm 0.084$ & .898 \\
\hline $\begin{array}{c}\text { Albumin }(\mathrm{mg} / \mathrm{dL}) \\
\text { Mean } \pm \text { SD }\end{array}$ & $3.82 \pm 0.154$ & $3.57 \pm 0.39$ & 0.001 \\
\hline $\begin{array}{c}\text { ACR }(\mathrm{mg} / \mathrm{g}) \\
\text { Mean } \pm \mathrm{SD}\end{array}$ & $.205 \pm .0184$ & $.141 \pm .017$ & $<0.001$ \\
\hline
\end{tabular}

Table.2 Correlations between ACR and parameters in cases group

\begin{tabular}{|l|c|c|}
\hline \multirow{2}{*}{ Age } & & ACR \\
\cline { 2 - 3 } & Sig. (2-tailed) & .340 \\
\hline \multirow{2}{*}{ MMI } & $\mathrm{R}$ & .143 \\
\cline { 2 - 3 } & Sig. (2-tailed) & -.012 \\
\hline \multirow{2}{*}{ Hemoglobin } & $\mathrm{R}$ & .961 \\
\cline { 2 - 3 } & Sig. (2-tailed) & .325 \\
\hline \multirow{2}{*}{ RBS } & $\mathrm{R}$ & .162 \\
\hline \multirow{2}{*}{ Albumin } & Sig. (2-tailed) & .304 \\
\cline { 2 - 3 } & $\mathrm{R}$ & .193 \\
\hline \multirow{2}{*}{ S. creatinine } & Sig. (2-tailed) & .293 \\
\cline { 2 - 3 } & $\mathrm{R}$ & .210 \\
\cline { 2 - 3 } & Sig. (2-tailed) & -.841 \\
\hline
\end{tabular}

This table shows a negative significant correlations between ACR and serum albumin in cases group. 


\section{DISCUSSION}

Our study aimed to investigate the presence of an association between proteinuria and active Helicobacter pylori infection in middle age non-diabetic patients.

In our study, H. Pylori infection had a high prevalence among our dyspeptic patients. Out of the 118 patients complaining from dyspepsia who had participated in our study; 59 patients $(50 \%)$ were found to be +ve for H. Pylori.

The prevalence of $\mathrm{H}$. Pylori infection differs from country to another, as regards to the socioeconomic standard and hygienic measures. A systematic review with metaanalysis done by Zamani et al. ${ }^{[13]}$ analyzed 410 879 participants from 73 countries within six continents showed that the overall prevalence of $\mathrm{H}$. Pylori infection was $44.3 \%$ worldwide. This rate ranged from $50.8 \%$ in developing countries compared with $34.7 \%$ in developed countries.

Another Systematic review with metaanalysis done by Hooi et al. ${ }^{[14]}$ collecting data from 62 countries showed that Africa had the highest pooled prevalence of $\mathrm{H}$ pylori infection $(79.1 \%)$, and according to this study the estimated prevalence in Egypt was about $40.9 \%$ of the general population. Based on the regional prevalence estimates, there were approximately 4.4 billion individuals with $\mathrm{H}$. Pylori infection worldwide in 2015.

The prevalence of $\mathrm{H}$. Pylori infection in Arabian countries differs from country to another. In Saudi Arabia, a study done by Saber et al. ${ }^{[15]}$ showed that the H. Pylori infection was diagnosed in $72.8 \%$ of the studied patients.

Another study in the same country done by Abo-shadi et al. ${ }^{[16]}$ showed that H. Pylori infection was detected in $64.7 \%$ of the gastric biopsy specimens from patients with upper gastrointestinal diseases.

On the other hand, another study done by Amer et al. ${ }^{[17]}$ showed a very high prevalence of H. Pylori infection in an Egyptian group estimated to be $91 \%$ of the studied group.

Another study done by Ibrahim et al. [18] found that a male predominance of $\mathrm{H}$. Pylori in both pediatric and adult populations and that association was higher in adults than in children,

In our study, there was no significant difference between the two studied groups regarding; BMI, systolic and diastolic blood pressure, the serum level of TLC, Platelets, RBG and Creatinine.

In our study, the serum hemoglobin level was significantly lower in our group of patients infected by $\mathrm{H}$. Pylori (mean $=10.51 \mathrm{mg} / \mathrm{dl}$ ) with a high statistical significance $(\mathrm{p}<0.001)$, in contrast to our control group who had a normal serum hemoglobin level $($ mean $=12.78 \mathrm{mg} / \mathrm{dl})$

Multiple meta-analyses had provided a convincing evidences that an association exists between $\mathrm{H}$. Pylori infection and iron deficiency anemia (IDA). A study done by $\mathrm{Xu}$ et al. ${ }^{[19]}$ included 17,791 patients in Beijing found that H. Pylori infection had a higher association with anemia and a lower level of hemoglobin among the studied patients.

Another study regarding this issue done by Muhsen \& Cohen ${ }^{[20]}$ revealed an increased risk for iron deficiency anemia among H. Pyloriinfected subjects.

On the other hand, many other studies found no relation between anemia and $\mathrm{H}$. Pylori infection including the study done by John et al. ${ }^{\text {[21] }}$ who did not found any association between IDA and $\mathrm{H}$. Pylori infection in adult population.

Although, the mean serum level of albumin was significantly higher in our control group $3.82 \mathrm{mg} / \mathrm{dl}$ compared to our case group 3.57 $\mathrm{mg} / \mathrm{dl}(\mathrm{p}=0.001)$, the serum level of albumin was still within normal level. In addition, there was a negative significant correlation between urinary Albumin / Creatinine ratio (UACR) and serum albumin in our case group.

This result is consistent with another study done by Caliskan et al. ${ }^{[22]}$ which was held to reveal the effect of Helicobacter Pylori eradication on proteinuria in patients with primary GN and revealed an elevation in the serum level of albumin after $H$. Pylori eradication. In this study the serum level of albumin was $34 \mathrm{~g} / \mathrm{l}$ before eradication and became $40 \mathrm{~g} / \mathrm{l}$ after eradication. $(\mathrm{p}=0.001)$ and it also had showed an improvement in the level 
of proteinuria after H. Pylori eradication which was also consistent with our study.

In our study we found that our infected group with $\mathrm{H}$. Pylori had a proteinuria slightly higher than normal level with a urinary Albumin / Creatinine ratio of $0.205 \mathrm{mg} / \mathrm{g}$ compared to the control group who had a UACR of $0.141 \mathrm{mg} / \mathrm{g} .(\mathrm{p}<0.001)$

Our study showed a significant higher proteinuria in $\mathrm{H}$. Pylori infected patients compared to non-infected individuals which was also consistent with some other studies.

Our results were consistent with the study of Aydogan et al. ${ }^{[23]}$ who demonstrated that the treatment of $\mathrm{H}$. pylori eradication significantly reduced the proteinuria within the normal limits. This refers to an impact of $\mathrm{H}$. Pylori infection on the pathogenesis of proteinuria.

Also our study is consistent with another study conducted by Tanriverd ${ }^{[24]}$ to examine the relationship between Helicobacter pylori infection and micro albuminuria in diabetic patients and found that Diabetic patients infected by Helicobacter pylori showed significantly higher micro albuminuria than non-infected patients.

Another case study related to this issue done by Sugimoto et al. ${ }^{[25]}$ showed that there was a marked reduction of proteinuria after eradication of gastric Helicobacter pylori infection in a patient with membranous nephropathy.

In contrast to our study, there was a study conducted in china by Kong et al. ${ }^{[26]}$ included 22,044 adults Chinese individuals and found that the prevalence of proteinuria and the overall CKD were not significantly different between these two studied groups (1.7 vs. $1.6 \%, \mathrm{P}=0.65$ and 3.0 vs. $2.7 \%, \mathrm{P}=0.2$ ). After adjusted for age, sex hypertension, diabetes, body mass index, uric acid, smoking drinking, total cholesterol, triglycerides, low-density lipoprotein cholesterol and high-density lipoprotein cholesterol the odds of decreased eGFR and proteinuria were not significantly different between the $\mathrm{H}$. Pylori positive and negative subjects.

In conclusion, Patients having $\mathrm{H}$. Pylori infection show a significant elevation in the January 2019 Volume 25 Issue 1 urinary albumin/creatinine ratio and a significant anemia suggesting a role of $\mathrm{H}$. Pylori infection in the pathogenesis of proteinuria and anemia.

\section{REFERENCES}

[1] Brown L.M. Helicobacter pylori: epidemiology and routes of transmission. Epidemiologic reviews, 2000; 22(2), pp.283-297.

[2] Tan H.J. and Goh K.L. Extra gastrointestinal manifestations of Helicobacter pylori infection: Facts or myth? A critical review. Journal of Digestive Diseases, 2012; 13(7), pp.342-349.

[3] Malfertheiner, M. V. Helicobacter pylori infection and the respiratory system: A systematic review of the literature. Digestion, 2011; 84(3), pp.212-220.

[4] Deerpaul, D. \& Hui, S.Y. The Study of Association between Helicobacter pylori ( $\mathrm{H}$. pylori) and Chronic Obstructive Pulmonary Disease (COPD). Journal of pulmonary \& respiratory medicine, 2014; 4(1), pp.1-14.

[5] Oleastro, M. \& Ménard, A. The Role of Helicobacter pylori Outer Membrane Proteins in Adherence and Pathogenesis. Biology, 2013; 2(1), pp.1110-1134.

[6] Mohamady O., Ramadan, N. \& Arnaout, H. The prevalence of helicobacter pylori infection in diabetic patients and its relation to the presence of gastrointestinal tract complications. International Journal of Academic Research, 2013; 5(4), pp.201-209.

[7] Bagirova, M, Allahverdiyev AM, Abamor ES, et al. An overview of challenges to eradication of Helicobacter pylori infection and future prospects. European Review for Medical and Pharmacological Sciences, 2017; 21, pp.2199_ 2219.

[8] Neelapu, N., Nammi, D., Pasupuleti, A., Surekha, C. Helicobacter Pylori Induced Gastric Inflammation, Ulcer, and Cancer: A Pathogenesis Perspective. Interdisciplinary Journal of Micro inflammation, 2014; 1(2), pp.1-7.

[9] Muhammad, J.S., Sugiyama, T. \& Zaidi, S.F., 2013. Gastric Pathophysiological Ins and Outs of Helicobacter pylori: A review. J Pak Med Assoc, 63(12), pp.1528-1533.

[10] Ibrahim, A., Zaher, T., Ghonemy, T., AbdElAzim, S. et al. Impact of CytotoxinAssociated Gene A of Helicobacter pylori Strains on Micro albuminuria in Type 2 Diabetes. Saudi Journal of Kidney Diseases and Transplantation, 2010; 21(4): pp.694-700.

www.zumj.journals.ekb.eg

-83- 
[11] Abbate, M., Zoja, C. \& Remuzzi, G. How does proteinuria cause progressive renal damage? Journal of the American Society of Nephrology, 2006; 17(11): pp.2974-2984.

[12] Kanbay, M., Kasapoglu, B. \& Akcay, A. An occult risk factor for proteinuria: Helicobacter pylori infection. Med Hypotheses, 2007; 69(3): pp.709-710.

[13] Zamani, M., Ebrahimtabar, F., Zamani, V., Miller, W., et al. Systematic review with metaanalysis: the worldwide prevalence of Helicobacter pylori infection. Alimentary Pharmacology \& Therapeutics, 2018; 47: pp.868-876.

[14] Hooi, J., Lai, W., Khoon, W., Suen, M., et al. Global Prevalence of Helicobacter pylori Infection: Systematic Review and MetaAnalysis. Gastroenterology, 2017; 153(2): pp.420-429.

[15] Saber, T., Ghonaim, M., Yousef, A., Khalifa, A., et al. Association of Helicobacter pylori CagA Gene with Gastric Cancer and Peptic Ulcer in Saudi Patients. J. Microbiol. Biotechnol, 2015; 25(7): pp.1146-1153.

[16] Abo-shadi, M.A., El-shazly, T.A. \& Al-johani, M.S. Clinical, Endoscopic, Pathological and Serological Findings of Helicobacter pylori Infection in Saudi Patients with Upper Gastrointestinal Diseases. British Journal of Medicine \& Medical Research, 2013; 3(4): pp.1109-1124.

[17] Amer F.A., El-sokkary, R., Elahmady, M., Gheith, T., Abdelbary, E. Helicobacter pylori genotypes among patients in a university hospital in Egypt: identifying the determinants of disease severity. Journal of Microbiology and Infectious Diseases, 2013; 3(3): pp.109115.

[18] Ibrahim, A., Morais, S., Ferro, A., Lunet, N., Peleteiro, B. Sex-differences in the prevalence of Helicobacter pylori infection in pediatric and adult populations: Systematic review and meta-analysis of 244 studies. Digestive and Liver Disease, 2017; 49(7); pp.742-749.

[19] Xu, M., Cao, B., Yuan, B., Yin, J., Liu, L., Lu, Q. Association of anemia with Helicobacter pylori infection: a retrospective study. Scientific Reports, 2017; 7(13434): pp.1-7.

[20] Muhsen, K. \& Cohen, D. Helicobacter pylori Infection and Iron Stores: A Systematic Review and Meta-analysis. Helicobacter, 2008; 13: pp.323-340.

[21] John, S., Baltodano, J., Mehta, N., Mark, K., Murthy, U. Unexplained iron deficiency anemia : does Helicobacter pylori have a role to play? Gastroenterology Report, 2018: pp.1-6.

[22] Caliskan, B., Yazici, H., Caliskan, Y., Ozluk, Y., Gulluoglu, M. et al. The effect of Helicobacter pylori eradication on proteinuria in patients with primary glomerulonephritis. Int J Nephro, 2014; 2014 pp.:180690.

[23] Aydogan, T., Ulas, T., Selcoki, Y., Alkan, R., Yilmaz, O., et al. Effects of Helicobacter pylori eradication on proteinuria: A prospective study. Wiener Klinische Wochenschrift, 2012; 124(78): pp.241-244.

[24] Tanriverd, Ö. Association of Helicobacter pylori infection with micro albuminuria in type 2 diabetic patients. Turk J Gastroenterol, 2011; 22(6): pp.569-574.

[25] Sugimoto, T., Furukawa, T., Maeda, T., Somura, M., Kashiwagi, A. Marked reduction of proteinuria after eradication of gastric Helicobacter pylori infection in a patient with membranous nephropathy: coincidental or associated? Intern Med, 2007; 46(17): pp.1483-1484.

[26] Kong, X., Xu, D., Li, F., Ma, X., Su, H., Xu, D. Association of $\mathrm{H}$. pylori infection with chronic kidney disease among Chinese adults. International Urology and Nephrology, 2017; 49(5): pp. $845-850$

How to cite this article: Balat MN, Zanaty MAF, EL-Antouny NG, Ahmed HK. Association Between Proteinuria and Active Helicobacter Pylori Infection in Non-Diabetic Patients. ZUMJ 2019; 25 (1); 79-84. 